\title{
Decreased occipital lobe metabolism by FDG-PET/CT
}

\author{
An anti-NMDA receptor encephalitis biomarker
}

\section{OPEN}

John C. Probasco, MD

Lilja Solnes, MD

Abhinav Nalluri, BS

Jesse Cohen, MD

Krystyna M. Jones, MD

Elcin Zan, MD

Mehrbod S. Javadi, MD

Arun Venkatesan, MD,

$\mathrm{PhD}$

Correspondence to

Dr. Probasco:

jprobas1@jhmi.edu
Supplemental data at Neurology.org/nn

\section{ABSTRACT}

Objective: To compare brain metabolism patterns on fluorodeoxyglucose (FDG)-PET/CT in antiNMDA receptor and other definite autoimmune encephalitis (AE) and to assess how these patterns differ between anti-NMDA receptor neurologic disability groups.

Methods: Retrospective review of clinical data and initial dedicated brain FDG-PET/CT studies for neurology inpatients with definite $A E$, per published consensus criteria, treated at a single academic medical center over a 10-year period. Z-score maps of FDG-PET/CT were made using 3-dimensional stereotactic surface projections in comparison to age group-matched controls. Brain region mean $Z$ scores with magnitudes $\geq 2.00$ were interpreted as significant. Comparisons were made between anti-NMDA receptor and other definite AE patients as well as among patients with anti-NMDA receptor based on modified Rankin Scale (mRS) scores at the time of FDG-PET/CT.

Results: The medial occipital lobes were markedly hypometabolic in 6 of 8 patients with antiNMDA receptor encephalitis and as a group $(Z=-4.02$, interquartile range [IQR] 2.14) relative to those with definite $A E(Z=-2.32,1.46 ; p=0.004)$. Among patients with anti-NMDA receptor encephalitis, the lateral and medial occipital lobes were markedly hypometabolic for patients with mRS 4-5 (lateral occipital lobe $Z=-3.69$, IQR 1; medial occipital lobe $Z=-4.08,1$ ) compared with those with $\mathrm{mRS} 0-3$ (lateral occipital lobe $Z=-0.83,2 ; p<0.0005$; medial occipital lobe $Z$ $=-1.07,2 ; p=0.001)$.

Conclusions: Marked medial occipital lobe hypometabolism by dedicated brain FDG-PET/CT may serve as an early biomarker for discriminating anti-NMDA receptor encephalitis from other AE. Resolution of lateral and medial occipital hypometabolism may correlate with improved neurologic status in anti-NMDA receptor encephalitis. Neurol Neuroimmunol Neuroinflamm 2018;5:e413; doi: $10.1212 / N X I .0000000000000413$

\section{GLOSSARY}

$\mathbf{A E}=$ autoimmune encephalitis; FDG = fluorodeoxyglucose; IQR $=$ interquartile range; $\mathbf{L E}=$ limbic encephalitis; $\mathbf{m R S}=$ modified Rankin Scale.

Anti-NMDA receptor encephalitis was described over a decade ago among women presenting with prodromal symptoms followed by the development of behavioral changes, hallucinations, memory deficits, seizures, decreased level of consciousness, and central hypoventilation, many of whom were found to have ovarian teratoma. ${ }^{1}$ Recent consensus criteria have emphasized the importance of recognizing the clinical presentation of anti-NMDA receptor encephalitis, incorporating MRI, EEG, and CSF analysis results. ${ }^{2}$

Included in original descriptions of anti-NMDA receptor encephalitis, ${ }^{1}$ 18F-fluorodeoxyglucose (FDG) PET has been recognized as a potentially useful biomarker in the initial evaluation and subsequent monitoring of patients with suspected autoimmune encephalitis (AE) and

\footnotetext{
From the Department of Neurology (J.C.P., A.N., J.C., A.V.), Johns Hopkins Encephalitis Center; Department of Neurology (J.C.P.), Johns Hopkins Center for Refractory Status Epilepticus and Neuroinflammation; and Russell H. Morgan Department of Radiology and Radiological Sciences (L.S., K.M.J., E.Z., M.S.J.), Johns Hopkins University School of Medicine, Baltimore, MD.

Funding information and disclosures are provided at the end of the article. Go to Neurology.org/nn for full disclosure forms. The Article Processing Charge was funded by the authors.

This is an open access article distributed under the terms of the Creative Commons Attribution-NonCommercial-NoDerivatives License 4.0 (CC BY-NC-ND), which permits downloading and sharing the work provided it is properly cited. The work cannot be changed in any way or used commercially without permission from the journal.
} 
is included in consensus criteria for definite autoimmune limbic encephalitis (LE), but not other forms of AE such as anti-NMDA receptor encephalitis. ${ }^{2,3}$ This in part is due to the uncertainty of the specificity and practicality of FDG-PET in the evaluation of $\mathrm{AE}$ in general and of particular forms of $\mathrm{AE}$, such as anti-NMDA receptor encephalitis. ${ }^{4}$ A gradient of anterior hypermetabolism to posterior cortical hypometabolism has been noted in anti-NMDA receptor encephalitis, although the specificity of this finding relative to other forms of $\mathrm{AE}$ is uncertain. ${ }^{5-8}$ In addition, isolated hypometabolism and hypermetabolism by FDG-PET have been reported in antiNMDA receptor encephalitis. ${ }^{5,6,9}$ When noted, the gradient of anterior hypermetabolism to posterior hypometabolism has been reported to resolve with improvement in patient functional status, but prior descriptions of these changes have been primarily qualitative rather than quantitative. ${ }^{9,10}$

We sought to semiquantitatively describe findings from dedicated brain FDG-PET/CT studies in patients with anti-NMDA receptor encephalitis compared with others with definite $\mathrm{AE}$ in the acute phase of illness. In addition, we sought to describe patterns of brain region metabolism in patients with antiNMDA receptor encephalitis with differing degrees of neurologic disability.

METHODS Standard protocols, approvals, and patient consents. This study was approved by the Institutional Review Board of Johns Hopkins University.

Patients. We identified admitted patients with AE who underwent FDG-PET/CT at Johns Hopkins Hospital through the course of their admission using the diagnostic terms "encephalitis" and "positron emission tomography" (PET) to search the administrative database (December 1, 2005, to March 15, 2016). Patients were cross-referenced with the Johns Hopkins Hospital PET/CT Center database. ${ }^{11}$

Patients were included if they underwent a brain FDG-PET/ CT study and had definite AE, including definite LE, per consensus criteria. ${ }^{2}$ Patients were defined as anti-NMDA receptor antibody positive if the anti-NMDA receptor antibody was detected in the serum and/or CSF. All seropositive patients were found to have a paraneoplastic or cell surface antibody in either the serum or CSF using commercially available antibody assays (Athena Diagnostics, Worcester, MA; Mayo Clinic Laboratories, Rochester, MN).

The electronic medical record was reviewed, and data collected included demographic information; neurologic symptoms and signs on presentation; diagnostic test results including serum and CSF paraneoplastic antibody assay results; modified Rankin
Scale (mRS) score at the time of the FGD-PET/CT study as a measure of neurologic disability; and whether corticosteroids or sedatives were administered within 24 hours preceding the FGD-PET/CT study. ${ }^{12,13}$ Blinded review of brain MRI was performed by 2 fellowship trained neuroradiologists (L.S. and E.Z.) as previously described. ${ }^{11}$

Brain FDG-PET/CT review. Blinded review of FDG-PET/ CT was performed by 2 board-certified nuclear medicine radiologists (L.S. and M.S.J.). As described previously, dedicated 10minute 3D brain FDG-PET/CT acquisitions were performed per institutional clinical protocol following whole body acquisition and did not require additional radiopharmaceutical dose administration. ${ }^{11}$ Qualitative and quantitative PET image analysis was performed using the commercially available database of more than 250 healthy controls, Cortex ID (GE Healthcare, Waukesha, WI). Z scores were calculated for standard brain regions, and these regions were also scored as normal, hypometabolic, or hypermetabolic by the 2 board-certified nuclear medicine radiologists. Patients younger than 30 years were compared with the lowest age group of controls for Z-score calculations. The following standard Cortex ID brain regions were used, as they could be reliably validated by radiologist visual inspection: caudate, cerebellum, frontal lobe, occipital lobe (designating the lateral occipital lobe), parietal lobe, temporal lobe, and visual cortex (designating the medial occipital lobe). If a region demonstrated an average $\mathrm{Z}$ score greater than 2.00 (i.e., greater than $2 \mathrm{SDs}$ from the mean for the healthy controls), FDG$\mathrm{PET} / \mathrm{CT}$ was recorded as quantitatively abnormal. The figures used in this article were generated using Cortex ID or the GE Advanced Workstation software package (GE Healthcare, Waukesha, WI).

Statistical methods. Associations between patient antibody status and patient demographics and initial brain FDG-PET/CT findings were assessed for continuous variables using the MannWhitney $U$ test and for categorical variables using the $\chi^{2}$ test or the Fisher exact test, as appropriate. For these 2-sided tests, $p<$ 0.05 was considered statistically significant.

The Mann-Whitney $U$ test with Bonferroni correction (significance set at $p<0.007$ ) was performed for multiple comparisons of brain region FDG-avidity on initial FDGPET/CT between anti-NMDA receptor and other definite AE patient groups; those ambulatory (mRS 0-3) vs nonambulatory or requiring assistance with ambulation (mRS 4-5) at the time of brain FDG-PET/CT; those treated with sedatives within 24 hours before brain FDG-PET/CT and those not; and those treated with corticosteroids within 24 hours before brain FDG-PET/CT and those not. The Kruskal-Wallis test with Bonferroni correction (significance set at $p<0.007$ ) was performed for multiple comparisons of brain region FDG-avidity between patients with anti-NMDA receptor encephalitis and those patients with antibodies directed against cell surface and intracellular antigens.

RESULTS Clinical characteristics of patients with definite AE who underwent brain FDG-PET/CT. Of 296 inpatients with the diagnosis of encephalitis, 61 were admitted after presenting with 12 weeks or less of symptoms and underwent brain FDG-PET/CT. Eight were found to have anti-NMDA receptor encephalitis and 21 were found to meet criteria for definite $\mathrm{AE}$ (including definite LE, table 1). Of the other patients 
Table 1 Patients with anti-NMDA receptor encephalitis or other definite autoimmune encephalitis admitted after presenting with 12 weeks or less of symptoms

\begin{tabular}{|c|c|c|c|}
\hline & $\begin{array}{l}\text { NMDA } \\
(\mathrm{N}=8)\end{array}$ & $\begin{array}{l}\text { Other definite } \\
A E(N=21)\end{array}$ & p Value \\
\hline Age, y, median (IQR) & 26 (13) & $59(44)$ & 0.02 \\
\hline Sex, female, n (\%) & $7(88)$ & 9 (43) & 0.04 \\
\hline Race, n (\%) & & & 0.62 \\
\hline Black & $2(25)$ & $3(14)$ & \\
\hline Other & 3 (38) & $6(29)$ & \\
\hline History or new diagnosis of cancer, $\mathrm{n}(\%)$ & 1 (13) & $6(29)$ & 0.64 \\
\hline Testicular & & 1 & \\
\hline Duration of neurologic symptoms before admission, wk, median (IQR) & $2(2)$ & $8(6)$ & 0.13 \\
\hline Duration of neurologic symptoms before brain FDG-PET/CT, wk, median (IQR) & $3(8)$ & $8(8)$ & 0.28 \\
\hline Modified Rankin Scale score of $4-5$ at the time of brain FDG-PET/CT, $n(\%)$ & 5 (63) & 7 (33) & 0.22 \\
\hline
\end{tabular}

Abbreviations: $A E$ = autoimmune encephalitis; $F D G$ = fluorodeoxyglucose; $I Q R=$ interquartile range.

with definite AE, 10 were found to have antibodies to cell surface proteins ( 4 anti-voltage-gated potassium channel complex antibodies without further specification, each meeting criteria for definite LE; 5 antileucine-rich glioma-inactivated 1 protein, 4 meeting criteria for definite LE; and 1 anti-aquaporin 4 meeting criteria for definite LE), and 11 had antibodies to intracellular proteins (4 anti-glutamic acid decarboxylase $65 \mathrm{kDa}, 3$ meeting criteria for definite LE; 2 anti-Ma2/Ta, both meeting criteria for definite LE; 3 antineuronal nuclear antibody $1 / \mathrm{Hu}, 2$ meeting criteria for definite LE; 1 anti-CV2/collapsing responsemediator protein 5; and 1 striational meeting criteria for definite LE).

Those with acute anti-NMDA receptor encephalitis were younger and more commonly women (median 26 years, interquartile range [IQR] 13; 7/ $8,88 \%$ ) than those with other acute definite $\mathrm{AE}$ (59 years, 44, $p=0.02$; 9/21, 43\%, $p=0.04$; table $1)$. One patient with anti-NMDA receptor encephalitis had a history of breast cancer. Otherwise both groups were well matched in terms of clinical characteristics including neurologic disability at the time of FDG-PET/CT (table 1).

In addition, 2 patients with anti-NMDA receptor encephalitis were hospitalized, who underwent brain FDG-PET/CT at greater than 6 months of symptoms (patients 9 and 10, table 2). These 2 patients were included in analyses of FDG-PET/CT brain metabolism patterns of patients with anti-NMDA receptor encephalitis in relation to the degree of neurologic disability at the time of the FDG-PET/CT study.
Brain FDG-PET/CT findings in acute anti-NMDA receptor encephalitis compared with other definite AE. There was no difference in the duration of symptoms before brain FDG-PET/CT between antiNMDA receptor encephalitis and other definite AE patient groups (3 weeks, IQR 8; 8 weeks, $8, p=$ 0.28 ; table 1 ). The rates of detection of abnormal metabolism were similar for those who underwent dedicated brain FDG-PET after 4 weeks or less of symptoms (12/14) compared with those who were studied at greater than 4 weeks of symptoms (15/15; $p=0.22$ ).

All 8 patients with anti-NMDA receptor encephalitis (figure 1) and 19/21 other patients with definite AE demonstrated abnormal metabolism on dedicated brain FDG-PET/CT $(p=1.00)$. Isolated brain region hypermetabolism was seen in $1 / 8$ antiNMDA receptor encephalitis (patient 6 , table 2, figure 1$)$ and $1 / 21$ patients with definite $\operatorname{AE}(p=$ $0.48)$. Isolated brain region hypometabolism was seen in 4/8 anti-NMDA receptor encephalitis (patients $1,4,5$, and 8 ; table 2, figure 1 ) and 15/21 other patients with definite $\mathrm{AE}(p=0.39)$. Brain regions with hypermetabolism in combination with other regions of hypometabolism in the same FDGPET/CT study were noted in 3/8 anti-NMDA receptor encephalitis (patients 2, 3, and 7; table 2, figure 1 ) and $3 / 21$ other patients with definite $\mathrm{AE}$ $(p=0.31)$.

Patterns of brain metabolism varied between patients with anti-NMDA receptor encephalitis and the other patients with definite AE. Visual cortical 


\begin{tabular}{|c|c|c|c|c|c|c|c|c|c|c|}
\hline \multirow[t]{3}{*}{ Table 2} & \multicolumn{10}{|c|}{ Demographics of patients with anti-NMDA receptor encephalitis who underwent dedicated brain FDG/PET CT (N = 10) } \\
\hline & \multirow{2}{*}{$\begin{array}{l}\text { Brain } \\
\text { FDG-PET/CT } \\
\text { Study }\end{array}$} & \multirow[b]{2}{*}{ Sex } & \multirow{2}{*}{$\begin{array}{l}\text { Age at the } \\
\text { time of the initial } \\
\text { admission, } y\end{array}$} & \multirow{2}{*}{$\begin{array}{l}\text { History of or } \\
\text { new cancer } \\
\text { diagnosis }\end{array}$} & \multirow{2}{*}{$\begin{array}{l}\text { Duration of } \\
\text { symptoms before } \\
\text { brain FDG-PET/CT, wk }\end{array}$} & \multirow{2}{*}{$\begin{array}{l}\text { Treated with sedative } \\
\text { within } 24 \mathrm{~h} \text { before brain } \\
\text { FDG-PET/CT }\end{array}$} & \multirow{2}{*}{$\begin{array}{l}\text { Treated with steroids } \\
\text { within } 24 \mathrm{~h} \text { before } \\
\text { brain FDG-PET/CT }\end{array}$} & \multirow{2}{*}{$\begin{array}{l}\mathrm{mRS} \text { at the } \\
\text { time of brain } \\
\text { FDG-PET/CT }\end{array}$} & \multicolumn{2}{|c|}{$\begin{array}{l}\text { Brain region with abnormal metabolism } \\
\text { on FDG-PET/CT }\end{array}$} \\
\hline & & & & & & & & & Hypermetabolism & Hypometabolism \\
\hline 1 & 1a & Female & 33 & & 2 & Yes & No & 5 & & $\begin{array}{l}\text { Cerebellum, frontal, occipital, parietal, } \\
\text { temporal, visual cortical }\end{array}$ \\
\hline 1 & $1 \mathrm{~b}$ & & & & 6 & No & No & 4 & & Caudate, frontal, temporal \\
\hline 1 & $1 \mathrm{c}$ & & & & 13 & No & No & 3 & & Caudate, frontal, temporal \\
\hline 1 & $1 d$ & & & & 30 & No & No & 2 & $\begin{array}{l}\text { Occipital, visual } \\
\text { cortical }\end{array}$ & \\
\hline 2 & 2 & Female & 20 & & 3 & No & Yes & 5 & Cerebellum & Occipital, visual cortical \\
\hline 3 & 3 & Male & 7 & & 1 & No & Yes & 5 & Caudate & Occipital, parietal, visual cortical \\
\hline 4 & 4 & Female & 57 & Breast & 12 & No & No & 3 & & $\begin{array}{l}\text { Cerebellum, frontal, occipital, } \\
\text { parietal, visual cortical }\end{array}$ \\
\hline 5 & 5 & Female & 22 & & 0 & Yes & Yes & 5 & & $\begin{array}{l}\text { Caudate, frontal, occipital, parietal, } \\
\text { temporal, visual cortical }\end{array}$ \\
\hline 6 & $6 a$ & Female & 29 & & 3 & No & No & 3 & Cerebellum & \\
\hline 6 & $6 b$ & & & & 27 & No & Yes & 3 & & \\
\hline 7 & 7 & Female & 31 & & 3 & No & No & 3 & Caudate & Temporal \\
\hline 8 & 8 & Female & 19 & & 11 & No & No & 5 & & $\begin{array}{l}\text { Frontal, occipital, parietal, visual } \\
\text { cortical }\end{array}$ \\
\hline 9 & 9 & Female & 25 & & 54 & Yes & No & 3 & & \\
\hline 10 & 10 & Male & 32 & & 28 & No & No & 1 & & \\
\hline
\end{tabular}

Abbreviations: FDG = fluorodeoxyglucose; $\mathrm{mRS}=$ modified Rankin Scale. 


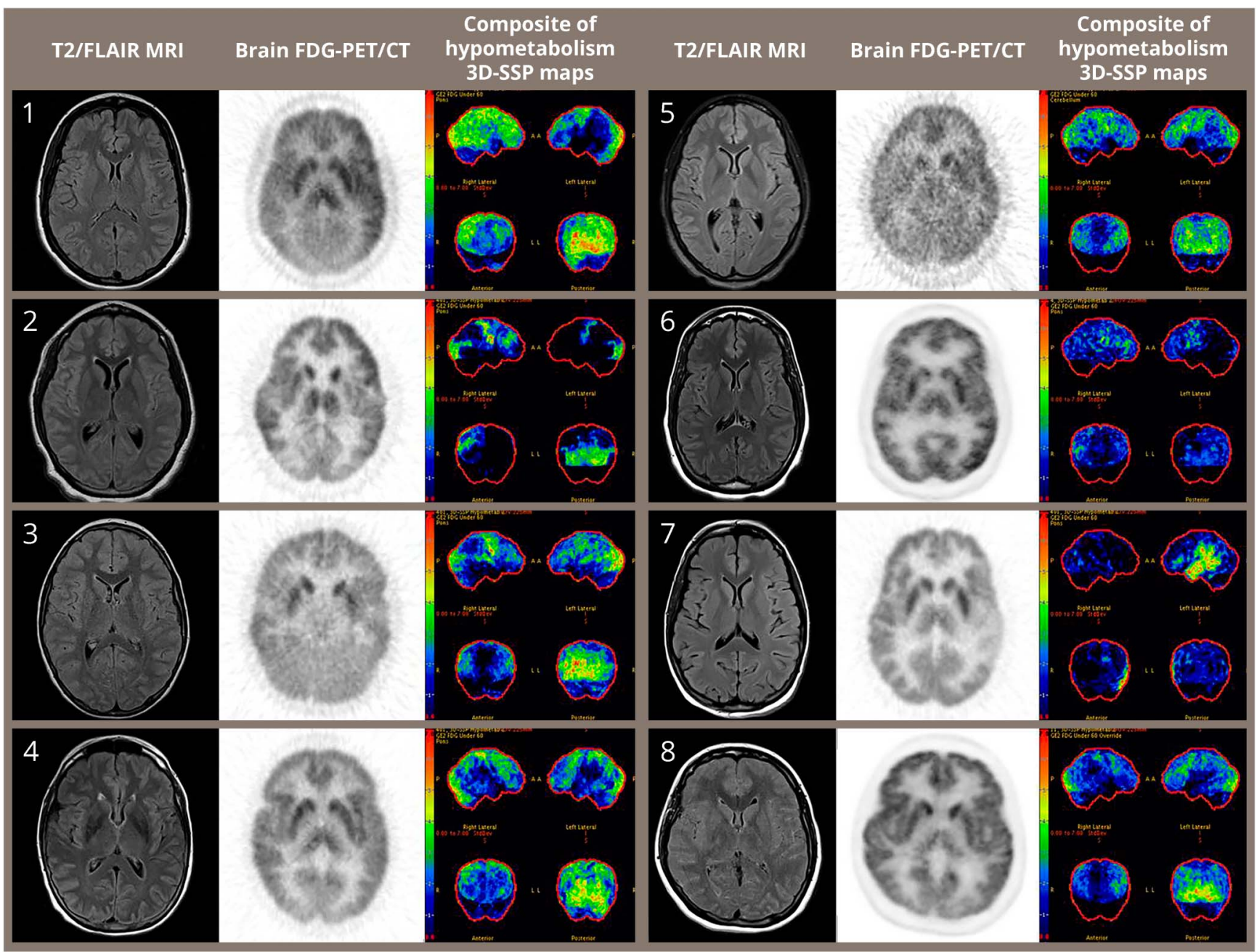

Initial brain fluorodeoxyglucose (FDG)-PET/CT of 8 patients with anti-NMDA receptor, studied within 12 weeks of symptoms. Composite of hypometabolism three-dimensional sterotactic surface projections (3D-SSP): indigo least abnormal and red most abnormal. FLAIR = fluid-attenuated inversion recovery.

brain regions, corresponding to the medial occipital lobes, were more hypometabolic for the patients with anti-NMDA receptor encephalitis (median brain region $\mathrm{Z}$ score $=-4.02$, IQR 2.14) relative to the other patients with definite $\mathrm{AE}(-2.32,1.47$; $p=0.004$; figure $2 \mathrm{~A})$. No other differences in brain region metabolism were noted between the 2 groups.

Similarly, when considering the antibody target location, the visual cortical brain regions of the patients with anti-NMDA receptor encephalitis were more hypometabolic compared with those seropositive for antibodies directed against other cell surface $(-2.22,1.06)$ or intracellular targets $(-2.41,3.47 ; p=0.01$, not significant on post hoc analyses; figure e-1 at Neurology.org/nn). No other differences in brain region metabolism were noted across antigenic target location groups.

When considering patient neurologic disability (table e-1), those patients with greatest neurologic disability (mRS 4-5) were more hypometabolic compared with those less disabled ( $\mathrm{mRS} 0-3$ ) in the visual cortical $(-3.10,1.55 ;-1.96,1.48 ; p<0.0005)$ and occipital brain regions $(-2.68,2.05 ;-2.05,1.90$; $p=0.04$, not significant on post hoc analyses, table e-1). Among those patients with mRS 4-5, the visual cortical and the occipital brain regions were more hypometabolic for the patients with anti-NMDA receptor encephalitis $(-4.08,0.68 ;-3.69,1.03)$ than those with other definite $\mathrm{AE}(-2.77,0.75$, $p=0.01 ;-1.92,1.54, p=0.01$, both not significant on post hoc analyses, table e-1). Similarly, the visual cortical regions and occipital brain regions of the patients with anti-NMDA receptor encephalitis were more hypometabolic than those seropositive for antibodies directed against other cell surface $(-2.93$, $0.58 ;-1.74,0.39)$ and intracellular targets $(-2.58$, $2.37, p=0.04 ;-2.17,2.78, p=0.03$, both not significant on post hoc analyses, table e-1). Cerebellar 


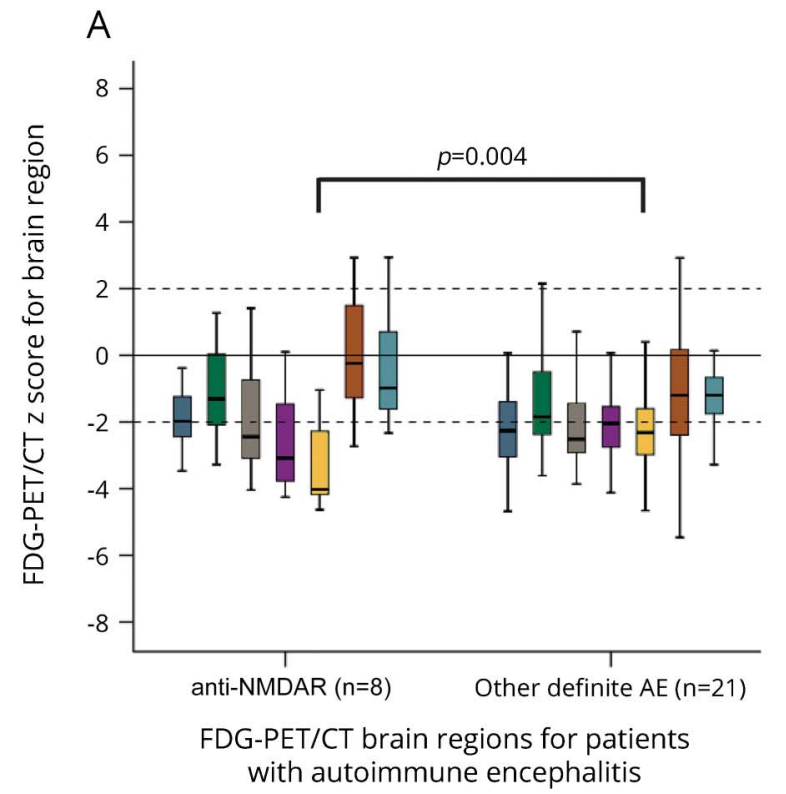

B

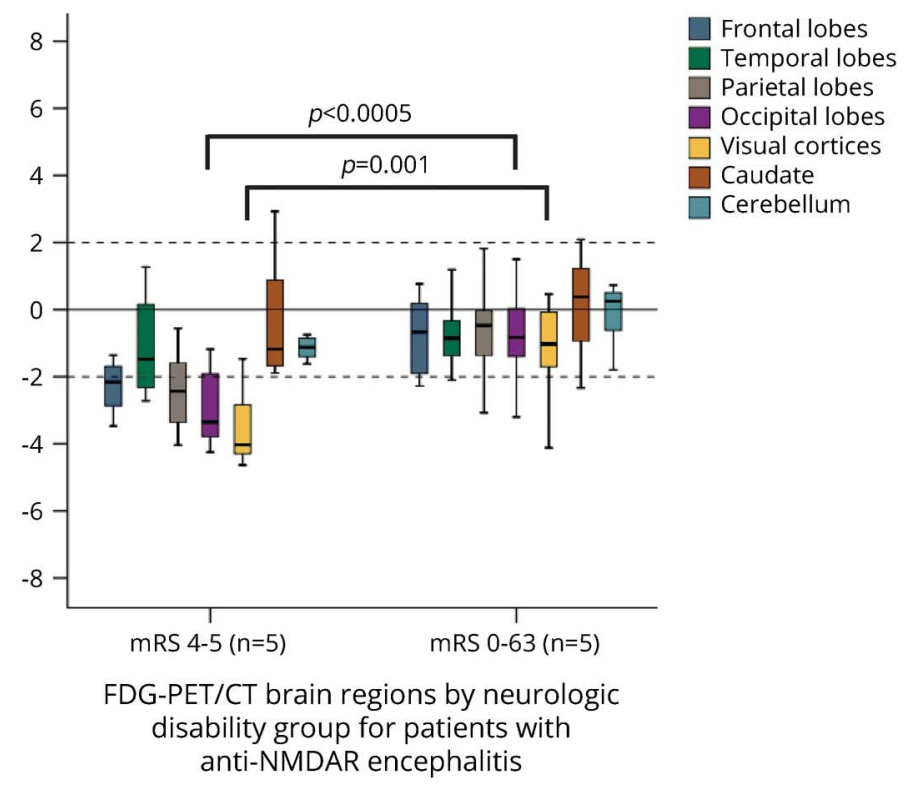

(A) Boxplots of $Z$ scores for fluorodeoxyglucose (FDG)-avidity for brain regions on dedicated FDG-PET/CT for patients admitted after presenting with 12 weeks or less of symptoms with anti-NMDA receptor and other definite AE. (B) Boxplots of Z scores for FDG-avidity for brain regions on initial dedicated brain FDG-PET/CT for all patients with anti-NMDA receptor encephalitis grouped by the modified Rankin Scale (mRS) at the time of the FDG-PET/CT study. $\mathrm{AE}=$ autoimmune encephalitis.

metabolism for the definite $\mathrm{AE}$ and the intracellular target groups were both less than that of the patients with anti-NMDA receptor encephalitis as a group; however, the group $\mathrm{Z}$ scores fell within the predefined normal range with Z-score magnitude less than 2.00 (table e-1).

Brain FDG-PET/CT findings in anti-NMDA receptor encephalitis between neurologic disability groups. Between anti-NMDA receptor encephalitis neurologic disability groups, the occipital lobe and visual cortical brain regions were more hypometabolic for patients with mRS 4-5 (occipital lobe median $\mathrm{Z}=$ -3.69, IQR 1; visual cortical $Z=-4.08,1)$ compared with those with mRS 0-3 (occipital lobe $Z=$ $-0.83,2, p<0.0005$; visual cortical $Z=-1.07,2$, $p=0.001$; figure $2 \mathrm{~B}$ and figure $\mathrm{e}-2$ ) on initial brain FDG-PET/CT. No other differences in brain region metabolism were noted between anti-NMDA receptor $\mathrm{mRS}$ groups (table e-2). Also, no differences in metabolism across brain regions were noted between those treated with sedatives or not, nor those treated with corticosteroids within 24 hours of brain FDG-PET/CT or not (table e-2).

DISCUSSION We describe dedicated semiquantitative brain FDG/PET findings among patients with anti-NMDA receptor encephalitis in comparison to other patients meeting recent consensus criteria for definite AE. Dedicated brain FDG-PET/CT was abnormal in all patients with anti-NMDA receptor encephalitis who were evaluated within 12 weeks of symptom onset. Brain region hypometabolism, in isolation or in combination with brain region hypermetabolism, was the most common finding in anti-NMDA receptor encephalitis, which is evident in 7 of 8 patients. Marked, 4 SDs from normal, medial occipital lobe hypometabolism was a unique finding in patients with anti-NMDA receptor encephalitis compared with other patients with definite $\mathrm{AE}$ who as a group were hypometabolic, but less dramatically so. Marked medial and lateral occipital lobe hypometabolism was evident in those patients with anti-NMDA receptor with severe neurologic disability (mRS 4-5) at the time of brain FDG-PET/CT, more so than those less neurologically disabled (mRS 0-3).

Abnormalities of brain metabolism by FDG-PET were noted in some of the initial case reports of anti-NMDA receptor encephalitis, including report of occipital hypometabolism. ${ }^{1}$ In adults and children with anti-NMDA receptor encephalitis, occipital hypometabolism has been most often described along with frontotemporal hypermetabolism, and the gradient of frontotemporal hypermetabolism to occipital hypometabolism has been reported to correlate with disease severity and normalize with treatment and recovery. ${ }^{5,6,9,14}$ Cortical hypometabolism with hypermetabolism of the basal ganglia has also been described. ${ }^{6,9,15}$ In light of the observations here, the previously observed 
anterior-to-posterior gradient may largely be driven by posterior hypometabolism rather than anterior hypermetabolism.

The specificity of the prior findings in anti-NMDA receptor is uncertain, given limited prior comparisons with other forms of AE. ${ }^{8,15}$ In our study, a direct semiquantitative comparison with other patients with definite $\mathrm{AE}$ was possible, using uniform brain FDG-PET/ CT equipment and protocols. Notably, the marked medial occipital hypometabolism observed among patients with anti-NMDA receptor encephalitis was not as evident in other AE.

This pattern of altered glucose metabolism in the lateral and medial occipital lobes observed by FDGPET/CT, most notably in the setting of greatest neurologic disability, is potentially consistent with prior descriptions of anti-NMDA receptor encephalitis pathogenesis as well as recent clinical descriptions. Antibodies directed at the NR1 subunit of the NMDA receptor characterize this form of encephalitis, the identification of which serves as the standard for diagnosis. ${ }^{16}$ These antibodies are thought to play a central role in the pathogenesis of anti-NMDA receptor encephalitis by mechanisms including the binding, capping, and cross-linking of NMDA receptors leading to internalization from the cell membrane surface and a selective decrease in NMDA receptor currents with no effect on synapse number or other synapse proteins. ${ }^{17,18}$ The effect of NMDA receptor internalization in anti-NMDA receptor encephalitis has been compared to that observed in the use of the dissociative anesthetics phencyclidine and ketamine, both antiNMDA receptor antagonists. ${ }^{18}$ Normal subjects administered subanesthetic ketamine doses and studied by brain FDG-PET have been noted to have increased relative metabolic rates in the frontolateral, frontomedial, and parietal cortices with decreased relative metabolism in the medial occipital cortex. ${ }^{19}$ In addition, in a recent cross-sectional study, patients with acute anti-NMDA receptor encephalitis were found to have diminished high-contrast and low-contrast visual acuity relative to matched healthy controls, with those more severely affected by anti-NMDA receptor encephalitis performing more poorly on visual acuity testing than those less affected..$^{20}$ Notably, the absence of evidence of retinal changes in these patients as assessed by optical coherence tomography suggests the possibility of visual cortical dysfunction. Together, these observations suggest that marked hypometabolism in the occipital cortex may be a distinctive feature of anti-NMDA receptor encephalitis, which was evident by dedicated brain FDG-PET/CT in the majority of patients.

A major limitation of this study is that it is retrospective, involving all patients meeting criteria for definite $\mathrm{AE}$ who underwent dedicated brain
FDG-PET/CT at a single tertiary center with associated selection bias. Although performed at a single center, it benefits from consensus inclusion criteria for definite $\mathrm{AE}$ and uniformity of PET equipment, protocols, and analyses. Not all patients underwent CSF antibody testing, and thus, we may have failed to include some patients with definite $\mathrm{AE}$, including those with anti-NMDA receptor encephalitis. In addition, FDG-PET/CT metabolism patterns of patients with anti-NMDA receptor encephalitis were compared with others with definite $\mathrm{AE}$, but not with other patients with neurologic disease, such as herpes simplex encephalitis. ${ }^{21,22}$ Of note, previous reports of FDG-PET in herpes encephalitis include acute hippocampal hypermetabolism with chronic focal hypometabolism, which is likely the result of gliosis and atrophy. ${ }^{21,23}$ Future prospective studies incorporating patients with other neurologic and psychiatric diseases are warranted to assess the specificity of metabolic findings by FDG-PET described here. Half of the patients with anti-NMDA receptor encephalitis included in this study were treated with either corticosteroids or sedatives within 24 hours of initial brain FDG-PET/CT. Although both corticosteroids and sedatives have been reported to decrease cortical metabolism, ${ }^{12,13}$ no difference in cortical metabolism were noted between those patients with anti-NMDA receptor encephalitis treated with these medication classes before their study and those who were not. In addition, prior studies of patients not treated with corticosteroids or sedatives demonstrated similar patterns of metabolism as presented here. ${ }^{5,6}$ As the duration of symptoms for the patients with anti-NMDA receptor encephalitis was less than the other patients with $\mathrm{AE}$, it is possible that the noted marked occipital hypometabolism would also be seen in the other definite AE patient groups if cerebral FDG-PET was performed earlier. Although no difference in the rate of abnormal metabolism was noted in those studied at 4 weeks or less of symptoms and those at more than 4 weeks of symptoms, the small sample size here did not allow for the definitive exclusion of the possible influence of disease duration on the rate of abnormal cerebral metabolism. Also, in those with greatest functional disability, there was a trend to a difference between the anti-NMDA receptor encephalitis and other AE groups, a difference to be explored prospectively. Finally, the control population used for comparison in Cortex ID software ranges from 30 to 85 years. Most patients with anti-NMDA receptor encephalitis presented here were younger than 30 years, as has been observed previously. ${ }^{24}$ Because cerebral metabolic activity decreases with age, ${ }^{25}$ the hypometabolism patterns noted here in a younger patient population may in fact underestimate the degree of 
abnormality. Ideally, a concurrent age- and sexmatched control population could be used for direct comparison, although such data collection is limited by the radiation exposure to otherwise normal patients.

Brain FDG-PET/CT is commonly abnormal in anti-NMDA receptor encephalitis, most often demonstrating marked hypometabolism of the medial occipital lobes. This marked hypometabolism of the medial occipital lobes is relatively unique to antiNMDA receptor encephalitis compared with other forms of definite $\mathrm{AE}$, particularly in those with greatest neurologic disability. Among patients with antiNMDA receptor encephalitis, marked lateral and medial occipital lobe hypometabolism is evident in those with severe neurologic disability compared with those less disabled. While detection of the antiNMDA receptor antibody in the CSF serves as the diagnostic biomarker of choice, medial occipital hypometabolism could potentially serve as a unique, noninvasive, early biomarker of anti-NMDA receptor encephalitis, with utility in diagnosis as well as monitoring of clinical improvement.

\section{AUTHOR CONTRIBUTIONS}

Dr. Probasco: design and conceptualization of the study, analysis and interpretation of data, and drafting and revising the manuscript. Dr. Solnes: design and conceptualization of the study, analysis and interpretation of data, and revising the manuscript. Mr. Nalluri: analysis and interpretation of data. Dr. Cohen, Dr. Jones, and Dr. Zan: analysis and interpretation of data and revising the manuscript. Dr. Javadi and Dr. Venkatesan: design and conceptualization of the study, analysis and interpretation of data, and revising the manuscript.

\section{STUDY FUNDING}

No targeted funding reported.

\section{DISCLOSURE}

J.C. Probasco serves on the editorial board, is an Associate Editor of The Neurohospitalist, and is the Editor-in-Chief of NEJM Journal Watch Neurology. L. Solnes, A. Nalluri, J. Cohen, K.M. Jones, E. Zan, and M.S. Javadi report no disclosures; A. Venkatesan served as a medical expert for the U.S. Government Vaccine Injury Compensation Program and received research support from the NIH. Go to Neurology.org/nn for full disclosure forms.

Received July 6, 2017. Accepted in final form August 28, 2017.

\section{REFERENCES}

1. Vitaliani R, Mason W, Ances B, Zwerdling T, Jiang Z, Dalmau J. Paraneoplastic encephalitis, psychiatric symptoms, and hypoventilation in ovarian teratoma. Ann Neurol 2005;58:594-604.

2. Graus F, Titulaer MJ, Balu R, et al. A clinical approach to diagnosis of autoimmune encephalitis. Lancet Neurol 2016;15:391-404.

3. Morbelli S, Djekidel M, Hesse S, Pagani M, Barthel H. Role of (18)F-FDG-PET imaging in the diagnosis of autoimmune encephalitis. Lancet Neurol 2016;15:1009-1010.

4. Graus F, Dalmau J. Role of (18)F-FDG-PET imaging in the diagnosis of autoimmune encephalitis-authors' reply. Lancet Neurol 2016;15:1010.
5. Leypoldt F, Buchert R, Kleiter I, et al. Fluorodeoxyglucose positron emission tomography in anti-N-methyl-D-aspartate receptor encephalitis: distinct pattern of disease. J Neurol Neurosurg Psychiatry 2012;83:681-686.

6. Lagarde S, Lepine A, Caietta E, et al. Cerebral (18)FluoroDeoxy-Glucose Positron Emission Tomography in paediatric anti N-methyl-d-aspartate receptor encephalitis: a case series. Brain Dev 2016;38:461-470.

7. Fisher RE, Patel NR, Lai EC, Schulz PE. Two different 18F-FDG brain PET metabolic patterns in autoimmune limbic encephalitis. Clin Nucl Med 2012;37:e213-e218.

8. Wegner F, Wilke F, Raab P, et al. Anti-leucine rich glioma inactivated 1 protein and anti-N-methyl-D-aspartate receptor encephalitis show distinct patterns of brain glucose metabolism in 18F-fluoro-2-deoxy-d-glucose positron emission tomography. BMC Neurol 2014;14:136.

9. Yuan J, Guan H, Zhou X, et al. Changing brain metabolism patterns in patients with ANMDARE: serial 18F-FDG PET/CT findings. Clin Nucl Med 2016; 41:366-370.

10. Probasco JC, Benavides DR, Ciarallo A, et al. Electroencephalographic and fluorodeoxyglucose-positron emission tomography correlates in anti-N-methyl-d-aspartate receptor autoimmune encephalitis. Epilepsy Behav Case Rep 2014;2:174-178.

11. Probasco JC, Solnes L, Nalluri A, et al. Abnormal brain metabolism on FDG-PET/CT is a common early finding in autoimmune encephalitis. Neurol Neuroimmunol Neuroinflamm 2017;4:e352. doi: 10.1212/NXI.0000000000000352.

12. Fulham MJ, Brunetti A, Aloj L, Raman R, Dwyer AJ, Di Chiro G. Decreased cerebral glucose metabolism in patients with brain tumors: an effect of corticosteroids. J Neurosurg 1995;83:657-664.

13. Matheja P, Weckesser M, Debus O, et al. Drug-induced changes in cerebral glucose consumption in bifrontal epilepsy. Epilepsia 2000;41:588-593.

14. Chen B, Wang Y, Geng Y, Huang Y, Guo S, Mao X. Marked improvement of anti-N-methyl-D-aspartate receptor encephalitis by large-dose methylprednisolone and plasmapheresis therapy combined with $18 \mathrm{~F}$-fluorodeoxyglucose positron emission tomography imaging: a case report. Exp Ther Med 2014;8:1167-1169.

15. Baumgartner A, Rauer S, Mader I, Meyer PT. Cerebral FDG-PET and MRI findings in autoimmune limbic encephalitis: correlation with autoantibody types. J Neurol 2013; 260:2744-2753.

16. Dalmau J, Tuzun E, Wu HY, et al. Paraneoplastic anti-Nmethyl-D-aspartate receptor encephalitis associated with ovarian teratoma. Ann Neurol 2007;61:25-36.

17. Hughes EG, Peng X, Gleichman AJ, et al. Cellular and synaptic mechanisms of anti-NMDA receptor encephalitis. J Neurosci 2010;30:5866-5875.

18. Dalmau J, Lancaster E, Martinez-Hernandez E, Rosenfeld MR, Balice-Gordon R. Clinical experience and laboratory investigations in patients with anti-NMDAR encephalitis. Lancet Neurol 2011;10:63-74.

19. Vollenweider FX, Leenders KL, Scharfetter C, et al. Metabolic hyperfrontality and psychopathology in the ketamine model of psychosis using positron emission tomography (PET) and [18F]fluorodeoxyglucose (FDG). Eur Neuropsychopharmacol 1997;7:9-24.

20. Brandt AU, Oberwahrenbrock T, Mikolajczak J, et al. Visual dysfunction, but not retinal thinning, following anti-NMDA receptor encephalitis. Neurol Neuroimmunol 
Neuroinflamm 2016;3:e198. doi: 10.1212/NXI. 0000000000000198.

21. Wong KK, Tolia B, Bohnen N. Chronic sequelae of herpes simplex encephalitis demonstrated on interictal F-18 FDG PET/CT. Clin Nucl Med 2008;33:443-444.

22. Hubele F, Bilger K, Kremer S, Imperiale A, Lioure B, Namer IJ. Sequential FDG PET and MRI findings in a case of human herpes virus 6 limbic encephalitis. Clin Nucl Med 2012;37:716-717.

23. Meyer MA, Hubner KF, Raja S, Hunter K, Paulsen WA. Sequential positron emission tomographic evaluations of brain metabolism in acute herpes encephalitis. J Neuroimaging 1994;4:104-105.

24. Titulaer MJ, McCracken L, Gabilondo I, et al. Treatment and prognostic factors for long-term outcome in patients with anti-NMDA receptor encephalitis: an observational cohort study. Lancet Neurol 2013;12: 157-165.

25. Petit-Taboue MC, Landeau B, Desson JF, Desgranges B, Baron JC. Effects of healthy aging on the regional cerebral metabolic rate of glucose assessed with statistical parametric mapping. Neuroimage 1998;7:176-184. 


\title{
Neurology \\ Neuroimmunology \& Neuroinflammation
}

\author{
Decreased occipital lobe metabolism by FDG-PET/CT: An anti-NMDA receptor \\ encephalitis biomarker \\ John C. Probasco, Lilja Solnes, Abhinav Nalluri, et al. \\ Neurol Neuroimmunol Neuroinflamm 2018;5; \\ DOI 10.1212/NXI.0000000000000413
}

This information is current as of November 15, 2017

Neurol Neuroimmunol Neuroinflamm is an official journal of the American Academy of Neurology.

Published since April 2014, it is an open-access, online-only, continuous publication journal. Copyright

Copyright (C) 2017 The Author(s). Published by Wolters Kluwer Health, Inc. on behalf of the American

Academy of Neurology.. All rights reserved. Online ISSN: 2332-7812.

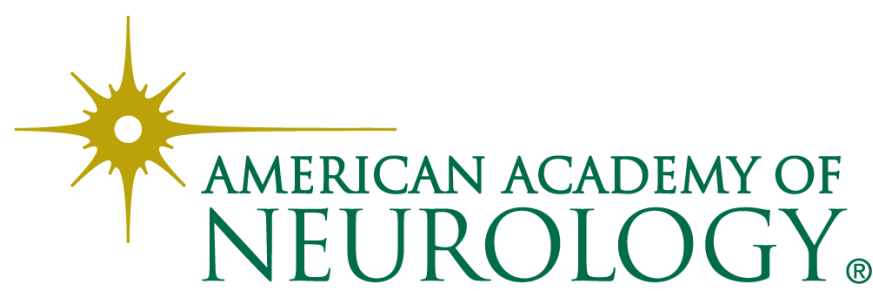




\section{Updated Information \& Services}

\section{Supplementary Material}

\section{References}

Citations

Subspecialty Collections

Permissions \& Licensing

Reprints including high resolution figures, can be found at: http://nn.neurology.org/content/5/1/e413.full.html

Supplementary material can be found at: http://nn.neurology.org/content/suppl/2018/01/04/5.1.e413.DC1

This article cites 25 articles, 2 of which you can access for free at: http://nn.neurology.org/content/5/1/e413.full.html\#\#ref-list-1

This article has been cited by 1 HighWire-hosted articles: http://nn.neurology.org/content/5/1/e413.full.html\#\#otherarticles

This article, along with others on similar topics, appears in the following collection(s):

\section{Encephalitis}

http://nn.neurology.org//cgi/collection/encephalitis

Paraneoplastic syndrome

http://nn.neurology.org//cgi/collection/paraneoplastic_syndrome PET

http://nn.neurology.org//cgi/collection/pet

Information about reproducing this article in parts (figures,tables) or in its entirety can be found online at:

http://nn.neurology.org/misc/about.xhtml\#permissions

Information about ordering reprints can be found online:

http://nn.neurology.org/misc/addir.xhtml\#reprintsus

Neurol Neuroimmunol Neuroinflamm is an official journal of the American Academy of Neurology.

Published since April 2014, it is an open-access, online-only, continuous publication journal. Copyright

Copyright $\odot 2017$ The Author(s). Published by Wolters Kluwer Health, Inc. on behalf of the American Academy of Neurology.. All rights reserved. Online ISSN: 2332-7812.

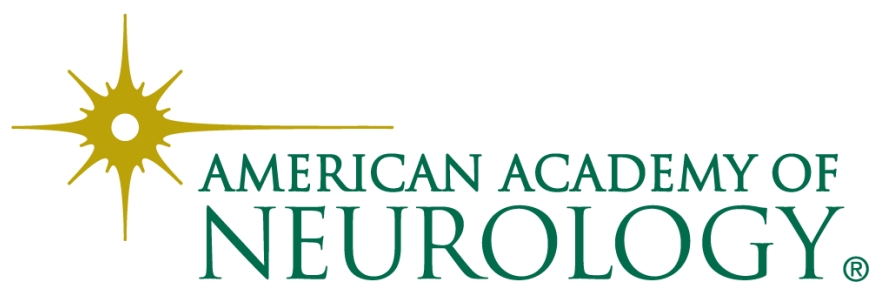

